\title{
Peer Interaction and Language Acquisition in German Kindergartens
}

\author{
Timm Albers \\ Karlsruhe University of Education \\ E-mail: albers@ph-karlsruhe.de
}

\section{Doi:10.5901/jesr.2013.v4n3p11}

\section{Abstract}

The purpose of this paper is to show the correlation between linguistic and communicative competencies of children in the everyday life of four German preschools. Particular attention is paid to the importance of the linguistic environment, which is constituted of the peer interaction and the interaction between children and early education specialists. A cross-sectional analysis using quantitative and qualitative methods was performed in the evaluation of the research questions. The findings especially highlight the major importance of access to peer interaction. Competent speakers therefore prove to be the most popular play partners within the same age group. However, also children at risk are capable of complex linguistic expression when they are especially interested in a subject or object, or if the early education specialists succeed in establishing a situation of "sustained shared thinking" (Siraj-Blatchford \& Sylva, 2004, p. 718).

Keywords: language acquisition; second-language acquisition; preschool; peer interaction; sustained shared thinking

\section{Introduction}

Under the present pressure for action in the elementary area exerted by the educational policies that the German states have presented and the discussion about meaningful surveys on language proficiency, early education specialists in Germany are currently faced with the challenge of developing facility-specific concepts in light of systematic information on language development and promotion in children in order to provide them with equal opportunities when entering school. The current controversy about the "right" method to determine language skills in children's daycare centers displays a strong polarization of standardized versus observation-guided survey methods that each focus on excerpts of linguistic or functional aspects of language (List, 2010).

The discrepancy between the demands of everyday language and formal school language is documented by estimates that children with a migration background had a 2.16 times higher risk of being referred to a special needs schools (Werning, 2010). In this sense, the support for early language diagnostics and language promotion appears to be justified: however, this must be specified with respect to the requirements of first- and second-language acquisition at the children's daycare centers. Progress is therefore constituted within a complex framework of requirements related to the linguistic competencies of children, in the provision and accompaniment of linguistic structures by pedagogical specialists, and in the various language-relevant situations that arise from peer interaction.

In the theoretical discussion about the influential factors of language acquisition, the psychological language development findings on the importance of linguistic inputs in preschool are initially presented in Chapter 2 . On the basis of the theoretically derived hypotheses, the issues in the present study are substantiated in the importance of the peer group and the early education specialists for language acquisition in preschool. Various diagnostic approaches (screening and spontaneous language data analysis) are compared in the methodical section (Chapter 3 ) in order to formulate recommendations for the diagnostics of linguistic and communication competencies within the context of complementing each of the respective methods. Implications for language diagnostics and promotion on the basis of the findings (Chapter 4) are presented as the conclusion (Chapter 5).

\section{Literature Review}

Children's daycare centers in Germany differ extensively in how they implement the task of supporting children as they acquire the language of their surrounding world. The pedagogic setting not only provides the institutional framework for linguistic interaction with regard to language acquisition; it is also an important introductory aide so that children can expand their linguistic- and communication-specific competencies: "The physical and social setting of the daycare and 
their particular group, and the children's activities not only framed the interactions but were a palpable part of them" (Katz, 2004, p. 334). The author mentions two significant conditional factors in her survey that influence the linguistic input in preschool: the quality of the teacher/child dialogs (see chapter 2.1) and the importance of dyadic and polyadic interactions (see chapter 2.2).

\subsection{Importance of Interaction between Early Education Specialist and the Child}

Even though a majority of studies on language acquisition focus particularly on the linguistic input within the mother child dyad, the spectrum of our environment in which language is learned must be seen in much larger terms. Children learn not only from their mother, but in dyadic and polyadic contexts of children, adults, and other reference persons (Lieven, 1994). Ritterfeld (2000) emphasizes the difference between generally beneficial and specific linguistically beneficial inputs that relate to the aspect of linguistic complexity in the language expression of the conversation partner on the one hand; on the other hand, they refer to a dialog-oriented interactive context because language rules can only be learned with communicative practice. However, the aspects of frequency and duration also play a role in addition to the quality of the linguistic input. This allowed Murray et al. (2006) to confirm the findings by Hart and Risley (1995) that language acquisition is dependent on both the quality and quantity of language inputs. While good language achievements are correlated with a high socioeconomic status for the family of origin (Hoff-Ginsberg, 2000), Murray et al. (2006) point out that a comparably high quality of linguistic input was found in children's daycare centers that were assigned to the group of "high-quality child care settings."

In the EPPE studies, Sylva et al. (2004) specify the effects of early nonparental child care on child development. Extended sustained shared thinking proves to be an effective pedagogical strategy to promote the cognitive development of children. The authors define this term as interactions in which two or more persons work together on the solution of a problem, evaluate activities, or develop a story (Siraj-Blatchford \& Sylva, 2004).

Based on the findings of interaction and interest research, Krapp (2002) attaches great value to the participation of individuals in the interaction process within this context. He emphasizes the willingness of the individual to engage in the interaction and direct attention toward it as an important indicator for supporting learning processes and establishing extended sustained shared thinking. Theoretical aspects of interest are closely associated within this context. According to Krapp (2002, p. 386), interest is characterized by the special relationship of a person to an object: "... interest is mostly understood as a phenomenon that emerges from an individual's interaction with his or her environment." In order to support these interactions, pedagogic specialists have the task of consciously approaching the children's thinking and establishing situations of shared thinking that are based on the children's interests.

\subsection{Importance of Peer Interaction}

Children develop peer cultures when interacting with the group of same-age children who are defined by two central aspects. According to the definition by Corsaro (2011, p. 15), these are the striving for self-determined structuring of their life and the pursuit of "sharing the fruits of their efforts with their peers." However, children's striving for self-determined interaction often also leads to processes of exclusion in preschool that are characterized by refusing to give other children access to their acts of play.

The inability to enter into a linguistic discourse with peers, to maintain it, or to act appropriately to conversational openings by peers can result in complete exclusion from (also non-verbal) interaction. Affected children develop compensatory coping strategies, in which they display a stronger dependence on adults or shorten their own contributions to dialogs (Rice, 1993). As a result, these children enter into a cycle that is characterized by the solidification of a negative self-image and social withdrawal. This is accompanied in turn by diminished linguistic input due to social exclusion.

Schuele and Rice (1995) consider the initiation of interactions as a decisive indicator of a child's linguistic and communicative abilities. Their research shows that children with specific language impairment (SLI) initiate significantly fewer conversations with their peers and that the length of the conversations is shorter in comparison to that of other children due to the lower degree of responsiveness. On the whole, a study by Rice (1993) showed that children with SLI are selected less frequently as conversation partners and their own attempts to establish interactions are twice as likely to meet with rejection in comparison to their linguistically competent peers. Even children at the age of three years already display high sensitivity to such language-specific differences in development within their peer group and choose their interaction partners depending on their linguistic and communicative skills (Grimm, 2002). 
The quality and complexity of dialogs between children is dependent on mutual experiences that are shared by the conversation partners (Short-Meyerson \& Abbeduto, 1997; Nelson \& Seidman, 1984). The duration of conversations between children is strongly dependent on whether they have a mutual "script" (Nelson, 2002), which means a thematic framework that is known to both interaction partners. When children are able to fall back on such a conversational framework and additionally possess elementary communication strategies (willingness to initiate conversation and turntaking), then they are capable of conducting conversational dialogs and maintaining them over an extended period of time (Short-Meyerson \& Abbeduto, 1997).

\section{Research methodology}

\subsection{Key Questions}

For a differentiated analysis of preschool-age children's linguistic and communicative competencies, it is important to identify the significance of linguistic input in language acquisition on the basis of theoretical deduction in addition to their language skills: The focus is therefore on both the education specialist/child interactions and the interactions within the peer group. If we assume that the early education specialist plays a significant role in language acquisition in children's daycare centers (Byalistok, 2007), then we need to examine whether the specialist succeeds in providing a languageand communication-promoting environment. Since a majority of the linguistic input is not generated within the specialist/child dyad but rather in conversational dialog with peers, this shows the importance of children's strategies that allow them to access peer interaction. The children's linguistic competence appears to be an influential factor of ensuring access to dyads in this process (Kreuzer, 2011). Consequently, the following key questions arise on the basis of these assumptions:

- Which strategies that influence language acquisition can be identified in the interaction between early education specialists and children of preschool age?

- Which strategies that affect language acquisition can be identified in peer interaction?

- What role do the children's linguistic proficiencies play in accessing peer interaction?

\subsection{Participants}

A total of 314 children from four children's daycare facilities in Germany were included in the study. Facilities that differ from each other with regard to the area that they serve (two rural, two urban) were selected. The sample consists of 164 boys (52.2\%) and 150 girls (47.8\%) between the ages of 3.0 and 5.9 years with an average age of 4.75 years. 35\% of the children experience a successive second-language acquisition of German (L2). German is the first language (L1) for $65 \%$ of the children. The largest group of children with a different family language than German is the group of Kurdishspeaking children (8.9\%), followed by children with the first language of Turkish (6.1\%), Russian (5.1\%), and Arabic (4.5\%). There are significant regional differences in the distribution of children who have German as their second language within the individual children's daycare centers. While the proportion of children in the process of gradually acquiring a second language is $11.5 \%$ at the rural children's daycare centers, it is significantly higher in urban facilities (55.4\%). Language-acquisition-specific conversation analysis was performed on the linguistic expressions of one child from each of the three sub-groups in the language screening conducted at the four participating children's daycare centers, which means that 12 highly detailed case studies were integrated into the survey.

\subsection{Instruments}

The first objective was to determine the linguistic competencies in the area of morphological and syntactic skills by using a standardized speech screening process (SSV) (Grimm, 2003). This also allowed for recording the linguistic competencies of children who were classified as linguistically skilled by early education specialists due to their positive communication behavior, although their grammatical skills would not be sufficient to follow the teaching of educational content in context-reduced situations. The language level of children who required assistance or therapy in urban facilities ( $n=60)$ was tested through SSV after eight months.

In a second step, a partial sample was taken from the identified sub-groups in order to perform a more detailed analysis of the spontaneous speech data in language-relevant everyday situations. 
On the one hand, the advantage of the participant observation performed within this context in comparison to the standardized observation methods is that it respectively allows the development of new research questions and generation of hypotheses dealing with the area of research by following the principle of openness. The combination of quantitative and qualitative methods correlates the results of the screening with the surveyed spontaneous speech data from the everyday life of the preschool.

On the other hand, the screening provides the opportunity to focus on the observation process by forming subgroups (normal, require assistance, and require therapy). This provides an answer to the question regarding the correlation between communicative strategies and language proficiencies by comparing the sub-groups that were identified during the screening.

\subsubsection{Quantitative Survey: Speech Screening}

The language screening for preschool children (SSV) developed by Grimm (2003) represents the short version of the German language development test for children from 3 to 5 years of age (SETK 3-5). The SETK 3-5 allows for a differentiated examination of the language development level and can be employed in cases where a comprehensive diagnosis is necessary; this subsequently serves as the basis for planning intervention measures. The two current short versions of SETK 3-5 each consist of two sub-tests that best represent the total test (Grimm, 2003): The version for 3year-old children records the phonological working memory for non-words (PMN) and the morphological rules (MR). Sentence memory (SM) is tested instead of morphological rules for 4-to-5 year olds. These short versions of the SETK 35 were adopted unchanged and share the complete test's content validity and all of the advantages of standardization. The manual indicates an internal consistency for the sub-tests of .62 and .89 respectively. The test validity was determined via a correlation with the SETK ( $r=.83$ and $r=.89)$. Sensitivity and specificity range between $80 \%$ and $97 \%$.

This screening process is designed to "record the most conspicuous development characteristics in terms of prognosis" (Grimm, 2003, p. 9), so it in no way replaces differentiated diagnostics. The screening in this study therefore primarily serves to identify receptive and productive language processing skills, as well as auditory memory performance, and to differentiate children with normal language development from those with a risk prognosis. The detailed analysis of linguistic competencies was performed using the qualitative conversation analysis illustrated in Chapter 3.3.3.

\subsubsection{Qualitative Survey: Participant Observation}

The core element of the procedure for participant observation is the personal participation of the researcher in the interactions of the individuals in the field of research. Certain aspects of behavior and situational construction of meaning can be observed this way that would otherwise not be accessible from an external perspective (Flick, 2008). However, in order to avoid the effect of excessive identification with the research object, which is also known as "going native," it is important to maintain a distanced and critical evaluation from the outside. The process of observation is structured to make this possible. Based on Flick (2008), four phases of observation are passed through in the process of concentrating on the key question. These phases are consolidated within the context of this study as follows:

- A: Descriptive observation initially serves the orientation within the area of investigation and does not yet provide focused descriptions in one topical field. It is used to record the complexity of the area as completely as possible and develop more concrete questions and perspectives in the process. The contact between early education specialists and children is established in this phase in order to build trust. Non-specific observations on the group structure and the atmosphere within the group can already be gathered here.

- B: The perspective increasingly narrows down to the important processes and phenomena for the concrete question during the focused observation. However, the survey phases are hard to differentiate from each other during the preschool's everyday activities: Observations that relate to language relevant situations in everyday preschool life can be gathered simultaneously during language screening.

- C: The selective observation near the end of the survey focuses on exploring additional evidence and examples for the behaviors and processes observed during the focused observation (Spradley, 1980). The results collected in the language screening are used to document the children's linguistic interactions in language-relevant situations and put them in relation to their linguistic competencies.

- D: Reflection on observations: The results are presented to the participating early education specialists and reflected upon with them. The findings of the language screening can be related to the subjective 
assessments by the specialists. The reflection phase serves as feedback for the observations in terms of validating the observation findings.

In order to ensure that all relevant aspects of an observation unit have been considered, it is helpful to use an observation guideline (Friebertshäuser, 2003). The guideline in this study is based both on the insights gathered in the observation's descriptive/exploratory phase and the questions and hypotheses that were developed in the theoretical concepts. The use of an observation guideline in the structuring of the observations appears appropriate despite the generally open approach in order to specify important theory-based observation dimensions in advance. Languagerelevant situations at children's daycare centers can be focused on the question as to what degree a child is actively involved and how he or she contributes to the linguistic communication based on the Sismik observation worksheet that was developed by Ulich und Mayr (2003). The categories illustrated in the following (pedagogic context, languagerelevant everyday situations, social-communicative competence of the specialists, social/communicative competence of children, and biographic orientation) complement the macro level of the conversation analysis (see Chapter 3.3.3):

- Group structure/pedagogic context: concept, group structure, formats in the daily routine, and reading picture books in dialog form

- Language-relevant everyday situations: at the breakfast table, in the free play time, conversations in the chair circle, and situations structured by the pedagogic specialist

- Social-communicative competence of the pedagogic specialists: responsiveness, use of correction and modeling techniques, dialog-oriented speech accompaniment, and situations of long sustained shared thinking

- Social-communicative competence with regard to interaction in the peer group: fundamental competence in game and interaction design with the peer group, symbolic and role plays, status in the peer group, competencies in initiation and responsivity, and establishing and maintaining dialogs.

- Biographic orientation: family language, number of contact months with second language (L2), siblings, and educational background of parents.

The observation guideline is intended as an instrument for focusing and sensitizing the theory-based categories. However, it provides freedom for the exploration of phenomena that is only possible inductively in contact with the subject of research. The difficulties of this method come to light within this context especially in the documentation of the observations: It becomes evident that not all aspects of linguistic interaction can be recorded during the concrete observation situation. Although the written documentation on site limits distortions and loss of the memory, it directs the observer's attention away from the observed situation toward his or her field notes (Friebertshäuser, 2003). In order to achieve the best possible documentation of linguistic interactions, audio recordings and field notes were used in parallel here. This method allows a specific analysis of the children's linguistic competence, yet contextual descriptions and nonverbal elements can be recorded as well. Video recording was not used due to the focusing on verbal elements of language and interaction, and with regard to the evaluation method of the linguistic conversation analysis.

\subsubsection{Evaluation Method}

The use of language screening, as well as the evaluation of the collected data, was performed according to the guidelines stipulated in the SSV test manual. The standardized test values have the advantage that they allow for comparison with the norming sample. The quantitative data analysis was performed with the statistics program SPSS (Version 19). Linguistic conversation analysis (Brinker \& Sager, 2006) is intended as a technique that aims to reconstruct discourses beyond words and sentences as the analytical categories of linguistics in everyday, natural communication situations. Participant observation offers a coherent methodical approach for interpreting the data in a context-related manner under this precondition, while linguistic conversation analysis provides the categories to describe authentic interactions with regard to their structure and function. This method aims to integrate and combine observation and interpretation processes: While observation processes are targeted toward selective control of perception and the empirical identification and focusing on selected phenomena, the emphasis of interpretation lies in the linking of phenomena by the identifying rules, patterns, and structures of which the research subjects are not directly aware (Reck, 1996). Linguistic conversation analysis can be deployed in these processes as a tool to separate observation from interpretation and to avoid spontaneous and location-based interpretation processes, but also to initiate reflexive, sequence-analytical, and comparative interpretation (Brinker \& Sager, 2006). The categories of the linguistic conversation analysis must be supplemented by the insights of first- and second-language acquisition in order to analyze the children's conversations. The method is therefore extended by language-acquisition-specific analysis categories and integrated into theory-based analysis levels within the context of this study. 
It appears to be necessary on this basis to initially analyze the micro level of the conversation analysis with regard to first- and second-language-acquisition theoretical features of lexical semantics and the syntax-morphologic language system. In relation to the meso level, the language-acquisition-specific complement of the method identifies the strategies with which the children use the rules and forms of communication with the help of pragmatic-communicative observation. The categories of the observation guideline (see 3.2.2) are integrated into the macro analysis in order to answer the question about social factors (specialist and peer group) influencing language acquisition.

\section{Findings and discussion}

\subsection{Presentation of the Quantitative Survey}

The descriptive presentation of the results from the language screening portray significant differences between children with German as their first or second language. As expected, children at the age of three years with a family language other than German attending a children's daycare center differ significantly with regard to their language skills in the common language from children who are acquiring German as their first language.

Figure 1. Comparing children with the first language of German (L1) $(\mathrm{N}=142)$ to children with German as a second language (L2) $(\mathrm{N}=80)$ in terms of who falls below critical values (in \%) of the sub-tests PMN, SM.

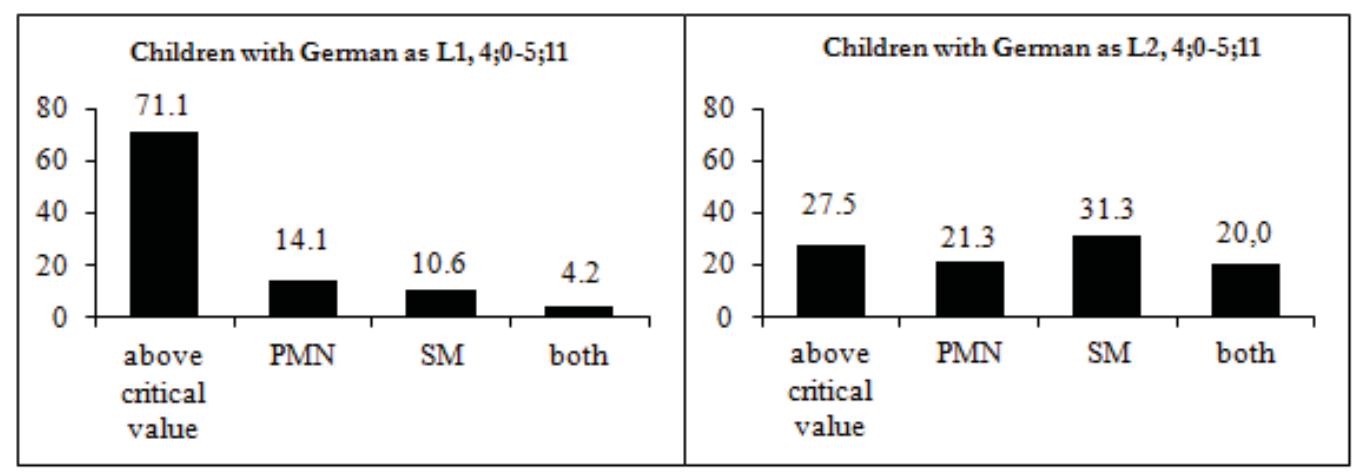

While $71 \%$ of the children from ages to four to almost six with German as their first language do not fall below critical values in either of the two sub-tests, this is the case for $28 \%$ of the children with a family language other than German. The different linguistic conditions of the four facilities become evident when looking at the average $T$ scores of the four samples in the SSV and their deviation from the average of the standard sample (Fig. 2). 
Figure 2. Average T-Scores and standard deviations related to the sub-tests (PMN, MR, SM) in the SSV. Notes: n.s.= not significant; ${ }^{*} p<.05 ;{ }^{* \star} p<.005 ;{ }^{* \star *} p<.001$

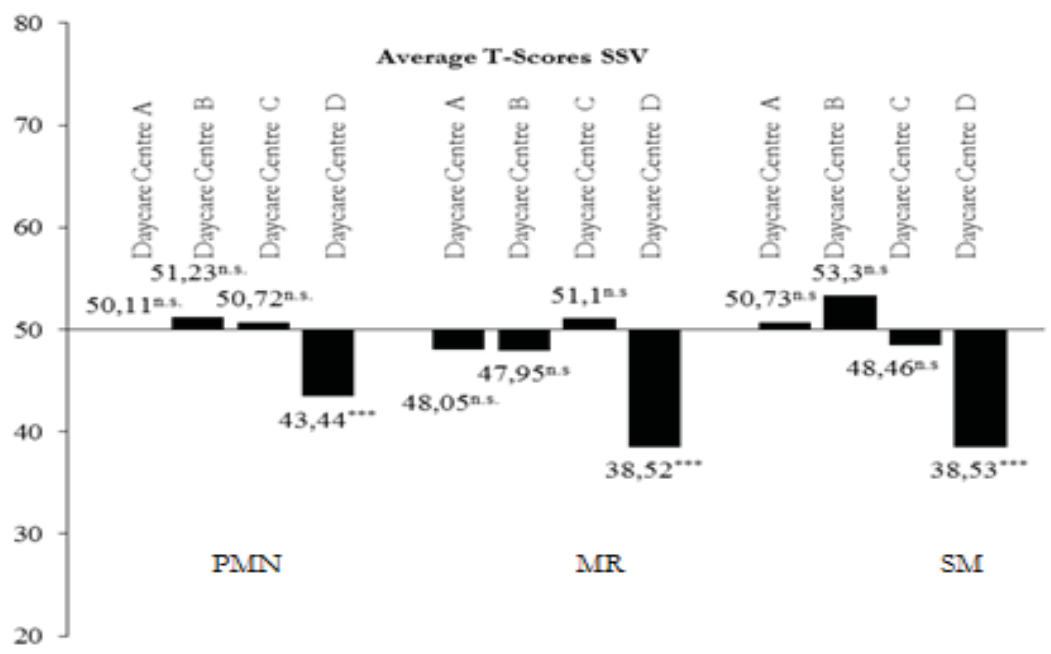

While the majority of the children in the children's daycare centers A (rural), B (urban), and C (rural) have developed linguistic competence in German as the language of instruction by the end of preschool age, which predicts successful attendance of school, the ratio in the group of children rated as language-competent is comparatively lower at children's daycare center $\mathrm{D}$ (urban, inner city preschool). The children attending preschool $\mathrm{D}$ apparently have significant deficits in comparison to children from the other three facilities and enter school with inadequate German language skills for the most part.

In order to assess whether the children with a need for assistance and therapy show signs of improvement at the first measurement point (t1) while attending preschool, the language screening was repeated eight months later (t2) in just the two urban facilities $(\mathrm{N}=60)$. A simple comparison of averages is intended to initially illustrate the development of language skills in children's daycare centers B and D. Then the main effects of "change over time," "group membership," (daycare B or D) and interaction effects of "time*group (gender, German as second language)" were to be tested in the variance analysis with repeated measuring.

Figure 3. Performance development: Average of the $T$ scores of all sub-tests at the measurement points of $t 1$ and $t 2$ $(\mathrm{N}=60)$. Notes: ${ }^{\star} \mathrm{p}<.05 ;{ }^{* *} p<.005 ;{ }^{* *} \mathrm{p}<.001$

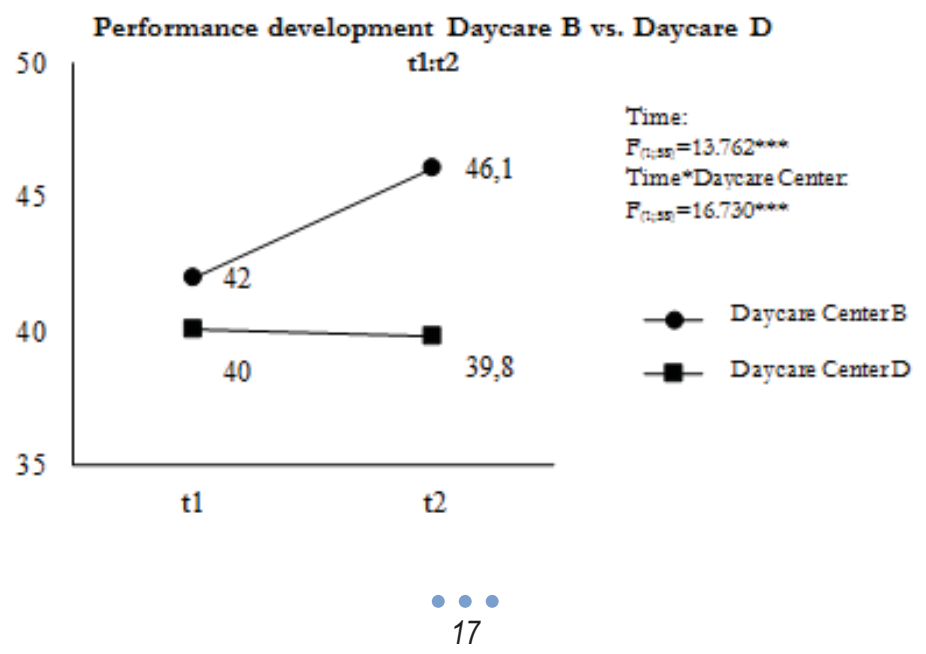


As shown in the figure, the two facilities differ with regard to the average T scores for children who fall below the critical level in one or two sub-tests by just two points at the measuring point t1. Just eight months later, this difference has increased to 6.3 points at the measuring point t2 (the group differentiation with regard to performance changes is significant at the .001 level).

Possible influential factors on the different development as control variables are calculated during the variance analysis with repeated measurements. As already shown, children with a family language other than German start their task of language acquisition in the language of the surrounding world with significantly worse conditions than children with German as their language of origin. This suggests that second-language acquisition represents the decisive factor for the expansion of German language competence.

Figure 4. Performance development: Average of all T scores of all sub-tests at the measuring points $\mathrm{t} 1$ and $\mathrm{t} 2(\mathrm{~N}=60)$ in the comparison of children with German as their first language (left) and German as their second language (right); significant differences are marked with "*": * $p<.05$; ${ }^{* \star} p<.005$; *** $p<.001$; n.s. = not significant

Children with German as L1

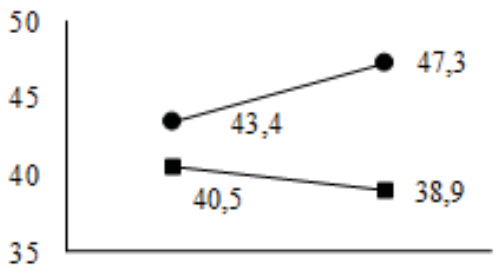

$\mathrm{t} 1$

t2

- Daycare Centre B
$\rightarrow-$ Daycare Centre D
Children with German as L2
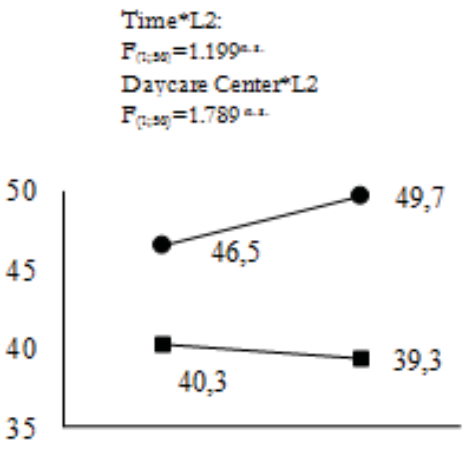

t1

t2

- D aycare Centre $B$
$\rightarrow-D$ aycare Centre D

When comparing the two facilities, second-language acquisition (Fig. 4) has apparently no significant influence on whether a child improves its skills in the common language of German within eight months in preschool. It is noticeable when comparing children's daycare centers $B$ and $D$ that children of daycare center B generally improve by an average T-score of 3.4 (second-language acquisition of German) to 3.9 points (first-language acquisition of German). Both subgroups in children's daycare center D worsen by one to two points (first- vs. second-language acquisition of German).

\subsection{Presentation of the Qualitative Survey}

In order to avoid a one-dimensional representation of written language texts, the method of Semi-Interpretive Working Transcriptions (HIAT) based on Rehbein and Ehlich (as cited in Brinker \& Sager, 2006) was developed, which is used in particular within the scope of functional-pragmatic discourse analysis and includes a scoring system as a form of notation. Through the depiction in score form makes it possible to graphically illustrate chronologically parallel relationships and also map simultaneous verbal and non-verbal actions. The various track types (speakers) are set up and assigned using the computer program EXMARaLDA. The methods of literary notation and modified orthographic transcription are used respectively for the transcription. It is possible to record meta information in the comment track in EXMARaLDA. This also includes information that describes the context of the interaction.

During the reflection on the results of the language screening, the early education specialists of preschool $D$ reported their assessment that the average linguistic skills of girls would be higher than those of the boys. The pedagogy team was clearly surprised during the presentation and analysis of the results by the fact that no statistically relevant difference between the language skills of boys and girls could be proven based on the data available from the first measuring point. This assessment by the early education specialists on the presumably higher linguistic competence of 
girls compared to boys probably leads to different behavior during the daily pedagogic routine, which explains why just boys were participating in the language promotion programs.

The linguistic behavior of pedagogic specialists is illustrated with the conversation transcript (see Fig. 5). The early education specialist uses open questions ("What would you like?" and "What else would you like?") and expanding statements ("Oh yes, that also tastes good"), which enable him or her to maintain the conversation with the child who has been identified as needing therapy. The specialist uses the context (at the breakfast table) in order to evoke words from the semantic area of "breakfast." She uses the strategy of corrective feedback carefully (Lena: "herbes"; Teacher: "Hm, with herbs") and presents the linguistic target structure without correcting her directly in the process. She succeeds in generating interest in the topic and using language-promoting strategies (correction and modeling techniques) in order to enter into a dialog with the child who rarely speaks.

Figure 5. Conversation extract from transcript of preschool A

\begin{tabular}{|c|c|c|}
\hline $\begin{array}{l}\text { Preschool } \\
\text { teacher }\end{array}$ & $\begin{array}{l}\text { What would you like, } \\
\text { Lena? }\end{array}$ & The cream cheese? \\
\hline Lena & & Cream cheese. \\
\hline Comonent & At breakfast & $\begin{array}{l}\text { Lena points to the } \\
\text { crean cbeese }\end{array}$ \\
\hline Analysis & Open question & \\
\hline \multicolumn{3}{|c|}{ (Continuation) } \\
\hline \begin{tabular}{|l|} 
Preschool \\
teacher
\end{tabular} & $\begin{array}{l}\text { Yummy, tasty. Do you } \\
\text { like cream cheese? }\end{array}$ & Yummy, me too. What do you like? \\
\hline Lena & & $\mathrm{Hm} \mathrm{hm}$. \\
\hline
\end{tabular}

\begin{tabular}{|c|c|c|}
\hline $\begin{array}{l}\text { Preschool } \\
\text { teacher }\end{array}$ & $\begin{array}{l}\text { That also on the } \\
\text { bread? }\end{array}$ & $\begin{array}{l}\text { Oh yes, } \\
\text { that also } \\
\text { tastes good }\end{array}$ \\
\hline Lena & Butter. & I like butter. \\
\hline Comowent & Open question & Expansion \\
\hline
\end{tabular}

(Continuation)
\begin{tabular}{|l|l|}
\hline Lena & Cream cheese, bread, jelly. My mommy also likes cream cheese, with herbes. \\
\hline Conment & Term differentiation \\
\hline
\end{tabular}

(continuation)
\begin{tabular}{|l|l|}
\hline $\begin{array}{l}\text { Preschool } \\
\text { teacher }\end{array}$ & Yummy, this also tastes great with herbs. And what does your daddy like best? \\
\hline Conment & Comrective feedback \\
\hline
\end{tabular}

The findings offer very few examples of sustained shared thinking: In a conversation between an early education specialist and children in a chair circle, the teacher introduces an impulse (earthworm) into the chair circle and uses open questions that require longer and more complex responses from the children ("Do you know why an earthworm is called an earthworm?") and also questions that can be answered by the younger children ("Where do you think I found this one?"). By doing so she adds information to the children's statements in order to expand ideas and suggestions (Marcel: "This is not called dirt. It's called soil! It eats the earth and then poops it out again." Teacher: "Yes, it eats plants that are in the soil."). The teacher succeeds in establishing sustained shared thinking and integrating the linguistically competent children and those who are less linguistically competent. Language is primarily used to regulate behavior and provide a reliable framework for the large number of speakers ("Please raise your hand. If you are very quiet, then I will call on you.").

Situations that can be considered language promoting due to their recurring structure and framework can be found in the dialogic reading of picture books. The teacher first instructs the children about behavior appropriate for the situation so that the context is structured, then establishes the interaction and creates excitement ("Look, put your knees like this and then it is more comfortable. Hush... I brought a story from the library. The story is called Lotte and the 
Monsters). When the children say something, the teacher listens attentively, establishes eye contact, and lets them finish speaking. The statements are valued, picked up by the teacher, and expanded in terms of their content ("Do you think so?", "I'm really curious. Let's see what's coming now."). If necessary, the children's statements are modeled (Timo: "Under bed."; Teacher: "Exactly, under the bed."). The children are integrated into the interaction by asking questions about the pictures and encouraged to respond ("Do you see these here?"; "They are bold, aren't they?"). She reacts in a friendly and confident way when dealing with conflicts (Timo: "I also can't see anything." Teacher: "It would be easier if everyone moves back a little." Timo: "Now I can see it. Now I saw it."). This leads to an overall sustained attention toward the children in comparison to the written language-dominated situation of reading out loud that is characterized by complex statements. At the same time, it allows language accompaniment by the children.

Although the situation of the dialogic picture book reading is characterized by a structured framework in which the specialist and the child can build a reference to the subject and establish theme-based dialog sequences, the structuring of a situation can result in abbreviated statements by the pedagogic specialist: A teacher instructs a language-promotion program that results in a clear hierarchy and a simple question/answer structure of the conversation. The specialist asks about the relationship between the picture cards and the respective initial sound of the object that is displayed on the cards. The structure of the program generally leads to one-word answers by the children and the teacher's language is instructional with regulating behavior and reduction of the linguistic complexity (short sentences and few subordinate clause constructions). Her feedback on the children's statements is partly wrong in the technical sense (she asks for the initial sound of "ice" (= ai). Teacher: "Yes exactly, that was pretty hard, right? It sounds a little like an A, but it also starts with an I.").

It becomes evident in the analysis of effective discourse strategies in adults that the use of sensitive correction and modeling techniques by qualified specialists leads to a successful extension of a child's contribution to a conversation. Situations of sustained shared thinking can be observed when the early education specialist uses the child's interest to enter into a dialog and maintain it.

The comparison of the case studies shows that children with a family language other than German are capable of maintaining conversations despite their limited flexibility in the language of the surrounding world and therefore evoke active linguistic structures in their environment. The following conversation excerpt from a case study at preschool $D$ is exemplary evidence of this situation (see Fig. 6 and 7).

\section{Figure 6. Case Study of Sarahnur}

\begin{tabular}{l} 
General information: Sarahnur is 3.6 years old at the time of the survey and has attended the preschool for the past six \\
months. Her language skills are graded below average with a T score of 32 on the PMN sub-test and a T score of 34 in \\
the SM sub-test. At the second measuring point, the T score in the PMN sub-test improves slightly to 33, but falls below \\
the critical value of 34 in the SM sub-test. The family language is Kurdish and both parents are able to communicate in \\
German with the teachers; however, they speak Kurdish exclusively at home. Sarahnur's twin sister Nadika is also in the \\
same preschool group. They also have a brother who is four years older than them with good German skills and a \\
newborn sister. \\
\hline Interpretation summary: During the observation of language-relevant everyday situations, Sarahnur speaks Kurdish with \\
her twin sister. She speaks German as soon as another child participates in the conversation. At the breakfast table she \\
responds to the children's questions and requests and actively participates in the conversations. The interaction \\
primarily takes place with children of the same age group, and she shows significant interest in role-playing games. \\
Sarahnur is a very popular play partner and gets actively involved in conversations. Sarahnur actively creates linguistic \\
input on her own through simple strategies (intonation of questions and repetition of core content words) by trying to \\
maintain the interaction for a long period of time.
\end{tabular}

All four children who are involved in the interaction illustrated in Figure 10 are attentive toward the speaker signals of their conversation partners, directly respond to questions, and relate to the contents of previous statements. However, Sarahnur's strategy of repeating core content words and phrases proves to be a particularly successful strategy for maintaining communication as she signals attention and shows interest in the conversation's subject. Despite the structural language difficulties, such a situation can result in sustained shared thinking (see Figure 7).

Figure 7. Conversation extract from preschool D 


\begin{tabular}{|l|ll|}
\hline Sarahnux & \multicolumn{3}{|c|}{ Youbaby? } \\
\hline Amila & $\begin{array}{l}\text { But I'm coming } \\
\text { tomorrow. Then I look } \\
\text { baby. }\end{array}$ & $\begin{array}{l}\text { I look baby. We } \\
\text { have... }\end{array}$ \\
\hline Convment & Conversation topic: siblings & Repetition of the conversation's core terms \\
\hline
\end{tabular}

(Continuation)
\begin{tabular}{|l|l|}
\hline Liana & \\
\hline Amila & All baby. This is my brother. Esra wants to marry the big brother. \\
\hline Comment & Extension of the topic \\
\hline
\end{tabular}

(Continuation)
\begin{tabular}{|l|ll|}
\hline Liana & Just joking - he already has two daughters. & \\
\hline Sarahnur & & The baby hair. A girl. \\
\hline Comoment & & Extension of tbe topic \\
\hline
\end{tabular}

(Continuation)
\begin{tabular}{|l|ll|}
\hline Liana & $\begin{array}{l}\text { See Katrin? She is also in the gro up. Katrin is } \\
\text { wearing glasses. }\end{array}$ \\
\hline Sarahnur & & Katrin. \\
\hline Comment & New conversation goal & Regetition of tbe conversation's core termus \\
\hline
\end{tabular}

(Continuation)
\begin{tabular}{|l|ll|}
\hline Liana & & \\
\hline Sarahnur & & Wes, hair. \\
\hline Amila & She has hair like that. & Exthe hair clips, little ones. \\
\hline Conment & Extension of the foovic & Extension of the tooic \\
\hline
\end{tabular}

(Continuation)
\begin{tabular}{|l|l|}
\hline Liana & Hair clips. \\
\hline Sarahnur & \multicolumn{1}{c|}{ Hair. } \\
\hline Connent & Regetition of the conversation's core termss \\
\hline
\end{tabular}

While the case studies indicate a multitude of communicative strategies used by the children that lead to polyadic and dyadic interaction, there are also noticeable behaviors in the social system of the preschool that serve to maintain complex play and interactive situations between language-competent peers with a simultaneous exclusion of less competent speakers. Elements from a case example (children's daycare center A) are used for illustrative purposes and then supplemented by a conversation extract (see Fig. 8 and 9).

\section{Figure 8. Case Study Alexander}

General information: Alexander is 5.5 years old at the time of the survey and has been attending the preschool for the
past two years. His language skills can be considered average with an average T value of 50.5. Russian is the family
language. His parents have lived in Germany for twelve years and both have a good command of German. Both
parents are employed: The mother works as a salesperson and the father as a mechanic. Alexander has no siblings.
Interpretation summary: Alexander often initiates conversations and role plays with the peer group and has a high
status within his preschool group. In the analysis of communicative strategies, it becomes evident that Alexander
already has metalingual knowledge and is able to assess the cause-and-effect relationships of linguistic statements.
He uses language purposefully to convey humor and express his emotions and needs. Furthermore, he also uses
linguistic statements as a tool of social exclusion by directly rejecting interaction attempts of unwanted play partners.

Figure 9. Conversation extract from preschool A 


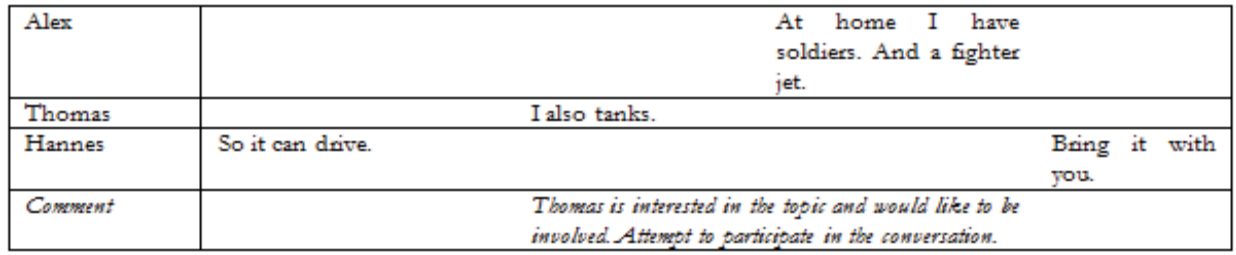

\begin{tabular}{|c|c|c|c|}
\hline Alex & $\begin{array}{l}\text { I want to } \\
\text { drink } \\
\text { something. }\end{array}$ & & $\begin{array}{l}\text { Mine has bombs. A bomb drops on the } \\
\text { tank and then it is busted. }\end{array}$ \\
\hline Thomas & & $\begin{array}{l}\text { Here, choc } \\
\text { (chocolate } \\
\text { milk). }\end{array}$ & \\
\hline Hannes & & $\begin{array}{l}\text { My tank is } \\
\text { strong. It } \\
\text { shoots down } \\
\text { the airplane. }\end{array}$ & \\
\hline Consment & & $\begin{array}{l}\text { Thomas offers the clbocolate wilk to } \\
\text { Alex. Alex does not accept it. }\end{array}$ & $\begin{array}{l}\text { Tbomas follows the conversation. After a sbort } \\
\text { period of time, be leaves the table witbout sajing } \\
\text { goodbe and returns to the growp. }\end{array}$ \\
\hline
\end{tabular}

Thomas, who is excluded from the interaction, is 5.9 years old at the time of the survey and has attended the facility for 2.7 years. His language skills are significantly below those of his peers with an average T score of 32.5. He fell below the critical value in the phonological memory of non-words sub-test with a score of 27 points. Thomas is repeatedly subject to social exclusion in interactions with the peer group, but he remains resilient in his attempts to establish and maintain conversations. He listens carefully in language-relevant everyday situations but rarely participates actively in conversations.

Thomas' low status in the peer group manifests itself in the repeated failure of his interaction attempts with his peers. He shows great interest in linguistic interaction, yet is sometimes actively excluded by more competent speakers. Since he is not able to identify language signals by the pedagogic specialists such as irony and provocation of objection as communicative strategies, no adequate response can follow. Although Thomas shows that he is capable of lengthy dyadic interaction with a girl in his preschool group, his interaction attempts receive no feedback and longer conversations or situations of shared thinking fail to arise. His major interest in peer interaction is reflected in his high emotional involvement and the repeated attempts to establish interaction.

In summary, it is apparent that a dialog-oriented interaction of the early education specialist with children also has a language-promoting importance in addition to providing them with motivating reasons to speak. In the interaction with adults and within their peer group, children learn to use the structural and communicative rules of language within a framework that is important to them.

\section{Concluding Remarks}

The data obtained in this study supports the construct of a Social Consequences Account developed by Rice (1993) in which linguistic competencies are viewed as the key to social interaction in the peer group. Children who are limited in their communicative skills due to a lack of linguistic variability prove to be especially vulnerable to rejection and exclusion processes in accordance with this. Compensatory strategies such as turning to the adults or an abbreviated responsive behavior in linguistic interaction consequently lead to faulty hypotheses regarding the lacking cognitive and social competence of a child with limited language skills. This applies to both the part of members of the peer group and the pedagogic specialists. As a result, these children are caught in a cycle that is characterized by a diminished experience of self-effectiveness as they retreat from peer interactions and develop the associated social-emotional disorders (Hadley et al., 1994).

A differentiated evaluation of the language screening's results requires the assessment of children who acquire German as a second language and have been in contact with the language of the surrounding world for just a short period of time: In order to differentiate between whether a child with a different language of origin is affected by a language acquisition disorder or whether the limited language skills are simply a result of having little exposure to the 
German language, it is imperative to evaluate the language level of the first language. This is the only way to avoid wrong assessments of special needs on the one hand and neglecting the needs of support measures for children who would really benefit from such programs on the other hand. Within the context of the findings of this study, children with a family language other than German do not have the structural linguistic competence to create complex sentence structures but they possess a multitude of communicative capabilities in order to gain access to linguistic interaction by using lexical techniques and social strategies.

Although the language screening and conversation analysis show a similar picture of the micro-structural competencies of children with German as a second language and German-speaking "children at-risk," they result in different prognoses of language development: Children with German as a second language have possibly already developed and successfully experienced communication strategies in their family language that they can now transfer successively to the second language. On the other hand, children with inadequate language skills who have been raised with German as the first language have possibly already experienced many cases of rejection when initiating peer interaction and have developed compensation strategies such as the preference of adults as interaction partners.

A survey of the case studies confirms the image that children's language acquisition is distinguished by an enormous variability (Szagun, 2008; Karmiloff \& Karmiloff-Smith, 2001), as it is characterized by the research literature. While the use of standardized screenings allows identification of children with inadequate German skills and children in need of therapy in the sense of an early intervention, a more detailed analysis of the linguistic competence and communicative strategies of the children and adults is required in order to make the most effective support possible in preschool. This speaks in favor of a combination of testing and observation methods in the early education area as the basis for optimal language promotion. However, the focus should not be on the education policy-driven strengthening of linguistic skills with regard to school entrance but rather on assisting a child's desire for peer relationships, selfdetermined interaction, and social participation (Corsaro, 2011). Based on the findings presented in this study, the child's linguistic and communicative competence appears to be a key factor in this process.

This represents an important insight for the pedagogic practice in children's daycare center: In addition to providing a linguistic and communicative relevant context in the preschool, access strategies to the children's peer cultures must also be created. They represent a large portion of the input from which children analyze and segment linguistic structures and then are able to integrate them into their own linguistic system. The pedagogic framework that is provided by preschool offers the best opportunities within this context, but is simultaneously the greatest challenge for pedagogic specialists: While important linguistic milestones are reached at the age of three to six years and early education concepts provide space for methods oriented upon everyday life that are appropriate for children to facilitate early language promotion, children of the preschool age develop their pursuit of self-determined interaction while simultaneously also acquiring strategies to remain in control of established play activities and to protect them from interferences. Ytterhus (2011, p. 127) refers to "the membrane between inclusive and exclusive interaction" in the peer group as very thin, but the instability of the structure in the social interaction with children can definitely be "adjusted to the right direction" (p. 128) by competent pedagogic specialists.

In order to structure appropriate pedagogic offers that are oriented upon the linguistic skills of the children, linguistic promotion on the basis of reliable data regarding the level of a child's language development is required. According to the presented findings, professionalization with respect to the design of dialogs with children that are based on the child's interest and facilitate processes of sustained shared thinking is especially necessary.

In conclusion, the qualification requirements of early education specialists must therefore be formulated within the context of language diagnostics and language promotion:

In terms of methods for determining language competence, the objective is to use the findings to evaluate the limited meaningfulness of testing procedures and develop criteria for evaluating standardized and reconstructive methods. For children with a language of origin other than German, knowledge about the process of acquiring a second language and the "stumbling blocks of German" (List, 2010, p. 11) is indispensable.

Language teaching strategies such as correction and modeling techniques must be conveyed with regard to their own role as an important part of the linguistic environment in the preschool in order to react appropriately and sensitively to the children's linguistic statements in keeping with their level of development. Creating a language-promoting environment through dialogic picture book reading and situations of sustained shared thinking in everyday preschool life is preferable to one-sided assistance through training programs. "The children's overall development can only be promoted by keenly observing and interpreting the children's language within the context of their actions and interactions, and by the children sensitively registering and acting upon the processing of the linguistic stimulation." (List, 2010, p. 47). 


\section{References}

Brinker, K. \& Sager, S. F. (2006). Linguistische Gesprächsanalyse. Berlin: Erich Schmidt.

Byalistok, E. (2007). Language Acquisition and Bilingualism. Consequences for a Multilingual Society. In: Applied Psycholinguistics, 28, pp. 393397.

Corsaro, W. A. (2011). Interpretative Reproduktion, Peer-Beziehungen von Kindern und ihr Verlangen nach selbstbestimmter Interaktion. In: M. Kreuzer \& B. Ytterhus (Ed.): "Dabeisein ist nicht alles" - Inklusion und Zusammenleben im Kindergarten, pp. 14-21. Munich: Reinhardt.

Flick, U. (2008). Triangulation. Wiesbaden: VS.

Friebertshäuser, B. (2003). Feldforschung und teilnehmende Beobachtung. In: B. Friebertshäuser \& A. Prengel (Ed.): Handbuch Qualitative Forschungsmethoden in der Erziehungswissenschaft, pp. 503-534. Weinheim: Juventa.

Fried, L. (2004). Expertise zu Sprachstandserhebungen für Kindergartenkinder und Schulanfänger. Munich: DJI

Jungmann, T. \& Fuchs, A. (2010). Sprachförderung. In: A. Lohaus \& H. Domsch (Ed.): Psychologische Förder- und Interventionsprogramme für das Kindes- und Jugendalter, pp. 63-74. Berlin: Springer.

Grimm, H. (2002). Störungen der Sprachentwicklung. Göttingen: Hogrefe.

Grimm, H. (2003). SSV. Sprachscreening für das Vorschulalter. Göttingen: Hogrefe.

Hadley, P. A., Wilcox, K. A. \& Rice, M. L. (1994). Talking at School: Teacher Expectations in Preschool and Kindergarten. In: Early Childhood Research Quarterly, 9, pp. 111-129.

Hart, B., \& Risley, R. T. (1995). Meaningful Differences in the Everyday Experience of Young American Children. Baltimore: Brookes.

Hoff-Ginsberg, E. (2000). Soziale Umwelt und Sprachenlernen. In: H. Grimm (Ed.): Enzyklopädie der Psychologie, Clll, Volume 3, Sprachentwicklung, pp. 463-494. Göttingen: Hogrefe.

Karmiloff, K. \& Karmiloff-Smith, A. (2001). Pathways to Language. From Fetus to Adolescent. Harvard: Harvard University Press.

Katz, J. R. (2004). Building Peer Relationships in Talk: Toddlers' Peer Conversations in Childcare. In: Discourse Studies, 6, pp. 329-346.

Krapp, A. (2002). Structural and dynamic aspects of interest development: theoretical considerations from an ontogenetic perspective. In: Learning and Instruction, 12, pp. 383-409.

Kreuzer, M. (2011). Zur Beteiligung von Kindern im Gruppenalltag von Kindergärten - Ein Überblick zu Ergebnissen deutscher Integrationsprojekte. In: M. Kreuzer \& B. Ytterhus (Ed.): "Dabeisein ist nicht alles" - Inklusion und Zusammenleben im Kindergarten, pp. 22-33. Munich: Reinhardt.

Lamnek, S. (2005). Qualitative Sozialforschung. Weinheim: Beltz.

Lieven, E. (1994). Crosslinguistic and crosscultural aspects of language addressed to children. I C. Gallaway \& B. J. Richards (Eds.): Input and Interaction in Language Acquisition, pp. 56-73. Cambridge: Cambridge University Press.

List, G. (2010). Expertise zu Qualifikationsanforderungen an frühpädagogische Fachkräfte im Arbeitsfeld Sprachförderung. Munich: Deutsches Jugendinstitut.

Murray, A. D., Fees, B. S., Crowe, L. K., Murphy, M. E. \& Henriksen, A. L. (2006). The Language Environment of Toddlers in Center-based Care versus Home Settings. In: Early Childhood Education Journal, 34, 3, pp. 233-239.

Nelson, K. (2002). Language in Cognitive Development. Cambridge: Cambridge University Press.

Nelson, K. \& Seidman, S. (1984). Playing with Scripts. In: I. Bretherton (Ed.): Symbolic Play: The Development of Social Understanding, pp. $45-$ 72. New York: Academic Press.

Reck, S. (1996). Schlüsselbegriffe der Kommunikationsanalyse. Weinheim: Deutscher Studienverlag.

Rice, M. L. (1993). Social Consequences of Specific Language Impairment. In: H. Grimm \& H. Skowronek (Eds.): Language Acquisition Problems and Reading Disorders: Aspects of Diagnosis and Intervention, pp. 111-128. New York: De Gruyter.

Ritterfeld, U. (2000). Welchen und wieviel Input braucht ein Kind? In: H. Grimm (Ed.): Enzyklopädie der Psychologie, CIII, Volume. 3 , Sprachentwicklung, pp. 403-432. Göttingen: Hogrefe.

Schuele, M. C. \& Rice, M. L. (1995). Redirects. A Strategy to increase Peer Interaction. In: Journal of Speech and Hearing Research, 38, pp. 1319-1333.

Short-Meyerson, K. \& Abbeduto, T. (1997). Preschoolers' Communication during Scripted Interactions. In: Journal of Child Language, 24, pp. 469-493.

Siraj-Blatchford, I. \& Sylva, K. (2004). Researching Pedagogy in English Preschools. In: British Educational Research Journal, 30 (5), pp. $713-$ 730.

Spradley, J. P. (1980). Participant Observation. New York: Holt, Rinehart \& Winston.

Sylva, K., Melhuish, E., Sammons, P., Siraj-Blatchford, I. \& Taggart, B. (2004). The Effective Provision of Pre-School Education [EPPE] Project. The EPPE Symposium at the British Educational Research Association (BERA). London: Institute of Education.

Szagun, G. (2008). Spracherwerb beim Kind: Was ist normal, was nicht? In: Kinder- und Jugendarzt, 1, pp. 6-8.

Ulich, M. \& Mayr, T. (2003). Die Sprachentwicklung von Migrantenkindern im Kindergarten - der Beobachtungsbogen SISMIK. In: Bezirksregierung Hannover (Ed.): Jugendhilfe in Niedersachsen Sonderausgabe 8: Sprachförderung im Kindergarten. Access on 06/21/2013. Available at http://cdl.niedersachsen.de/blob/images/C2885338_L20.pdf.

Werning, R. (2010). Inklusion: Chancen, Widersprüche, Perspektiven. Access on 06/30/2013. Available at www.hss.de/downloads/ 10051618_RM_Werning.pdf.

Ytterhus, B. (2011). Das Kinderkollektiv' - Eine Analyse der sozialen Position und Teilnahme von behinderten Kindern in der Gleichaltrigengruppe. In: M. Kreuzer \& B. Ytterhus (Ed.): "Dabeisein ist nicht alles" - Inklusion und Zusammenleben im Kindergarten, pp. 112-131. Munich: Reinhardt. 